\title{
A Critical Review of Published Data on the Gas Temperature and the Electron Density in the Electrolyte Cathode Atmospheric Glow Discharges
}

Pál Mezei $^{1, *}$ and Tamás Cserfalvi ${ }^{2}$

1 Institute for Solid State Physics and Optics, Wigner Research Centre for Physics, Hungarian Academy of Sciences, H-1525 Budapest, P.O. Box 49, Hungary

2 Aqua-Concorde Water Analysis R\&D LLC, T. Meisel Laboratory, Budapest, Hungary; E-Mail: cserfalvi@yahoo.com

* Author to whom correspondence should be addressed; E-Mail: mezei.pal@wigner.mta.hu; Tel.: +36-1-392-22-22-(1692); Fax: +36-1-392-22-15.

Received: 24 April 2012; in revised form: 8 May 2012 / Accepted: 16 May 2012 /

Published: 18 May 2012

\begin{abstract}
Electrolyte Cathode Discharge (ELCAD) spectrometry, a novel sensitive multielement direct analytical method for metal traces in aqueous solutions, was introduced in 1993 as a new sensing principle. Since then several works have tried to develop an operational mechanism for this exotic atmospheric glow plasma technique, however these attempts cannot be combined into a valid model description. In this review we summarize the conceptual and technical problems we found in this upcoming research field of direct sensors. The $\mathrm{T}_{\mathrm{G}}$ gas temperature and the $\mathrm{n}_{\mathrm{e}}$ electron density values published up to now for ELCAD are very confusing. These data were evaluated by three conditions. The first is the gas composition of the ELCAD plasma, since $T_{G}$ was determined from the emitted intensity of the $\mathrm{N}_{2}$ and $\mathrm{OH}$ bands. Secondly, since the ELCAD is an atmospheric glow discharge, thus, the obtained $T_{G}$ has to be close to the $T_{e}$ electron temperature. This can be used for the mutual validation of the received temperature data. Thirdly, as a consequence of the second condition, the values of $T_{G}$ and $n_{e}$ have to agree with the Engel-Brown approximation of the Saha-equation related to weakly ionized glow discharge plasmas. Application of non-adequate experimental methods and theoretical treatment leads to unreliable descriptions which cannot be used to optimize the detector performance.
\end{abstract}

Keywords: direct multielement sensor; metals in water; atmospheric glow plasma 


\section{Introduction}

The electrolyte cathode atmospheric glow discharge (ELCAD) technique was invented for the direct measurement of metals $(\mathrm{Zn}, \mathrm{Cd}, \mathrm{Cu}, \mathrm{Ni}, \mathrm{Cr}, \mathrm{Pb}$, alkali and earth metals, $\mathrm{Fe}, \mathrm{Mn}$, etc.) in aqueous samples [1]. In the case of ELCAD, the sample solution is the cathode and a W-rod above it (3-5 mm) is the anode. Under atmospheric air pressure, a d.c. glow discharge is produced (Figure 1). The atomic lines of metals dissolved in the solution appear in the spectrum emitted by the ELCAD, and in this way the concentration of metals in a sample can be determined. Since the cathode sputtering consumes the sample solution, the maintenance of a constant electrode distance, thus a stable discharge operation requires a constant flow rate of cathode solution [1].

The atomic emission having very narrow emitted lines provides excellent possibilities for the simultaneous multimetal detection of up to 20-30 elements. In a flow injection analytical system, the capillary ELCAD detector reached approximately $1 \mathrm{ng}$ mass detection limits (14-34 ng/mL) for heavy metals [2]. Later, in a continuous-flow method, the limits of detection are reported to be between $0.8-350 \mathrm{ng} / \mathrm{mL}$ for 16 metals ranging from $\mathrm{Na}$ to $\mathrm{Hg}$ [3].

Figure 1. The CCD camera picture of the typical ELCAD plasma operating between the electrolyte cathode and the $\mathrm{W}$ anode [4].

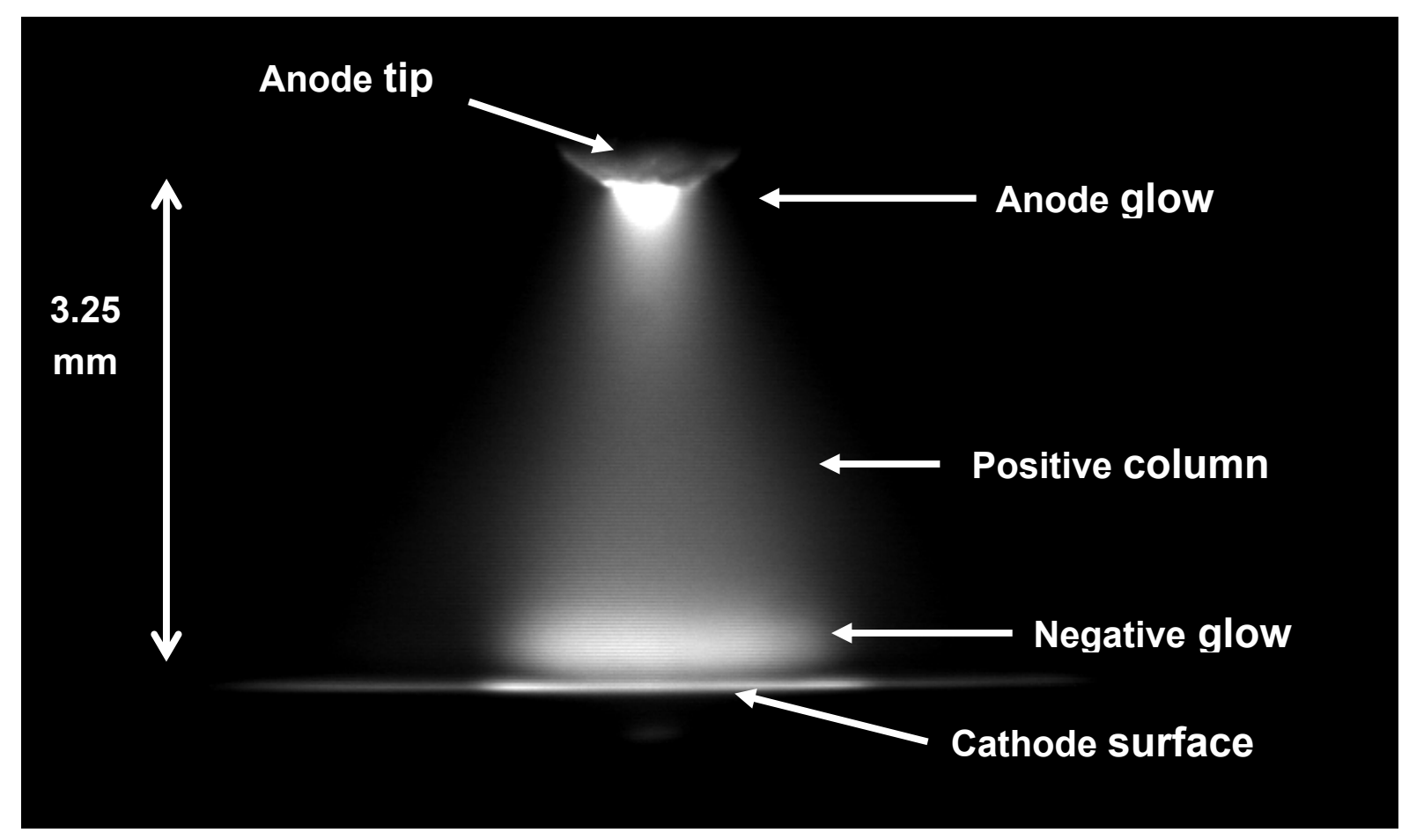

The emitted intensity of the atomic lines of metals dissolved in the cathode solution, which have a maximum in the negative glow region, are determined by the pressure, the current and the solution $\mathrm{pH}$, hence fall also on the cathode [4-6]. This was explained by the fact that the $\mathrm{M}^{+}$positive metal ions leave the cathode solution due to the cathode sputtering. In the cathode dark space, these $\mathrm{M}^{+}$ions are recombined by the reaction $\mathrm{M}^{+}+2 \mathrm{e} \rightarrow \mathrm{M}+\mathrm{e}$. The rate of this recombination is inversely proportional to the $\mathrm{kT}_{\mathrm{e}}$ average electron energy [7]. The produced neutral $\mathrm{M}$ metal atoms diffuse into the negative glow, where they are mainly excited by electron impact [4-6]. 
On the other hand, the $\mathrm{T}_{\mathrm{G}}$ gas temperature and the $\mathrm{n}_{\mathrm{e}}$ electron density also influence the emitted intensity of the atomic metal lines. $\mathrm{T}_{\mathrm{G}}$ relates to the gas particle density, the collision number between the electrons and the gas particles, the mean free path of electrons and hence the electron energy gained in this distance [8-10]. In this way, the $\mathrm{T}_{\mathrm{G}}$ and the $\mathrm{n}_{\mathrm{e}}$ are two basic parameters of the ELCAD plasma determining the operation and the excitation mechanisms, hence the emitted intensities as well.

In the case of the ELCAD and its homologue plasmas, the $\mathrm{T}_{\mathrm{G}}$ was determined mainly by means of the emitted band of $\mathrm{N}_{2}$ molecule and $\mathrm{OH}$ radical, while the $\mathrm{n}_{\mathrm{e}}$ was studied by various methods. The published data, however, are very confusing, covering $\sim 3$ orders of magnitude in $n_{\mathrm{e}}$ values and $\sim 1$ order of magnitude in $\mathrm{T}_{\mathrm{G}}$ values [3,4,6,11-20,21].

The evaluation of the available data was based on the following three conditions:

(1) In order to offer an accurate method for the determination of $T_{G}$, the gas composition of the ELCAD plasma was studied.

(2) Since the ELCAD is an atmospheric glow discharge, hence for $\mathrm{T}_{\mathrm{G}}$ and $\mathrm{T}_{\mathrm{e}}$ electron temperature, $\mathrm{T}_{\mathrm{G}}=\mathrm{T}_{\mathrm{e}}[22,23]$ or $\mathrm{T}_{\mathrm{e}} \approx \mathrm{T}_{\mathrm{G}}$ [24-26] can be expected. If $\mathrm{T}_{\mathrm{e}}$ is also measured, $\mathrm{T}_{\mathrm{e}}=\mathrm{T}_{\mathrm{G}}$ or $\mathrm{T}_{\mathrm{e}} \approx \mathrm{T}_{\mathrm{G}}$ relation can be used for the mutual validation of the received values.

(3) As a consequence of the $T_{e}=T_{G}$ (or $T_{e} \approx T_{G}$ ) relation referring to an local thermodynamic equilibrium (LTE) [22,23] (or a good approximation of it [24-26]), the corresponding values of $T_{G}$ and $n_{e}$ can be calculated from the Engel-Brown approximation $[8,10]$ of the Saha-equation $[27,28]$ related to the weakly ionized glow discharges with low charge densities.

\section{The Published $\mathbf{T}_{G}$ and $\mathbf{n}_{\mathrm{e}}$ DATA}

The data presented in Table 1 are evaluated by means of the three conditions mentioned above.

Table 1. The published $\mathrm{T}_{\text {rot }} \approx \mathrm{T}_{\mathrm{G}}$ rotational (gas), $\mathrm{T}_{\mathrm{e}}$ electron temperature and $\mathrm{n}_{\mathrm{e}}$ electron density values showing the measuring place $(\mathrm{NG}=$ negative glow, $\mathrm{PC}=$ positive column, $\mathrm{NAR}=$ near anode region), the determination method, the type of discharge and the references.

\begin{tabular}{|c|c|c|c|c|}
\hline$T_{\text {rot }} \approx T_{G}[K]$ & $\mathbf{T}_{\mathrm{e}}[\mathbf{K}]$ & $\mathrm{n}_{\mathrm{e}}\left[\mathrm{cm}^{-3}\right]$ & type of discharge & Ref. \\
\hline $\begin{array}{l}\text { NAR: } \mathbf{6 , 0 0 0} \\
\text { PC: } \mathbf{4 , 8 0 0} \\
\text { NG: } 7,000 \\
\text { OH emission, } \\
\text { Izarra method }\end{array}$ & $\begin{array}{l}\text { NAR: } \mathbf{6 , 0 0 0} \\
\text { PC: } \mathbf{5 , 5 0 0} \\
\text { NG: } \mathbf{7 , 0 0 0} \\
\text { Int. ratio of } 510.5,515.3 \mathrm{~nm} \\
\text { Cu lines }\end{array}$ & $\begin{array}{l}\text { NG: } \mathbf{1 0}^{\mathbf{1 3}} ; \mathbf{3} \times \mathbf{1 0}^{\mathbf{1 3}} \\
\text { Calculated from the } \\
\text { operating parameters }\end{array}$ & Original ELCAD & {$[6,21]$} \\
\hline $\begin{array}{l}\text { NAR, PC: } \mathbf{1 , 0 0 0} \\
\text { NG: } \mathbf{2 , 0 0 0} \\
\mathrm{N}_{2} \text { emission }\end{array}$ & $\begin{array}{l}\mathbf{4 , 0 0 0} \\
\text { Intensity ratio of } \\
\text { H-Balmer lines } \\
\end{array}$ & $\begin{array}{l}\text { PC: } 4 \times 10^{11} \\
\text { NG: } 7 \times 10^{11} \\
\text { Microwave absorption }\end{array}$ & liquid electrodes & [11-14] \\
\hline $\begin{array}{l}\mathbf{1 , 8 0 0} \\
\mathrm{N}_{2} \text { emission }\end{array}$ & & $\begin{array}{l}\mathbf{7} \times \mathbf{1 0}^{\mathbf{1 2}} \\
\text { Calculated from current } \\
\text { density, temperature }\end{array}$ & $\begin{array}{l}\text { a.c. excited } \\
(v=60 \mathrm{~Hz}) \\
\text { ELCAD like }\end{array}$ & {$[15]$} \\
\hline $\begin{array}{l}\text { PC: } \mathbf{3 , 2 0 0} \\
\text { NG: } \mathbf{3 , 6 0 0} \\
\text { OH emission } \\
\text { Boltzmann plot }\end{array}$ & $\begin{array}{l}\text { PC: } \mathbf{2 , 5 0 0} \\
\text { NG: 5,000 } \\
\text { from Fe-I lines, } \\
\text { Boltzmann-plot; } \\
\text { Saha-equation }\end{array}$ & $\begin{array}{l}\text { PC: } 2.5 \times \mathbf{1 0}^{14} \\
\text { NG: } 8.5 \times \mathbf{1 0}^{14} \\
\text { Stark broadening } \\
\text { of H-486.1 nm line }\end{array}$ & ELCAD type & {$[3,16]$} \\
\hline
\end{tabular}


Table 1. Cont.

\begin{tabular}{|c|c|c|c|c|}
\hline $\begin{array}{l}\text { PC: } \mathbf{3 , 2 5 0} \\
\text { NG: } \mathbf{3 , 4 0 0 - 3 , 6 0 0} \\
\text { OH emission } \\
\text { PC: } \mathbf{3 , 2 5 0} \\
\text { NG: } \mathbf{2 , 2 0 0 - 2 , 8 0 0} \\
\mathrm{N}_{2} \text { emission }\end{array}$ & $\begin{array}{l}\mathbf{6 , 1 0 0} \\
\text { Intensity ratio of } \\
\mathrm{H}_{\alpha} \text { and } \mathrm{H}_{\beta} \text { lines }\end{array}$ & $\begin{array}{l}\text { NG: } \\
\mathbf{( 5 . 5 - 9 )} \times \mathbf{1 0}^{\mathbf{1 4}} \\
\text { Stark broadening } \\
\text { of } \mathrm{H}-486.1 \mathrm{~nm}\end{array}$ & ELCAD like & [17-19] \\
\hline $\begin{array}{l}\mathbf{1 , 7 0 0} \\
\mathrm{N}_{2} \text { emission } \\
\mathbf{2 , 2 0 0 - 3 , 2 0 0} \\
\mathrm{OH} \text { emission }\end{array}$ & $\begin{array}{l}\mathbf{5 , 5 6 5} \\
\text { calculated from } \\
\text { OH vibr. level population }\end{array}$ & $\begin{array}{l}\mathbf{1 0}^{\mathbf{1 3}} \\
\text { calculated from } \\
\text { current distribution }\end{array}$ & $\begin{array}{l}\text { ELCAD like with } \\
\text { distilled water cathode }\end{array}$ & [20] \\
\hline
\end{tabular}

\section{The Evaluation of the Published $T_{G}$ and $n_{e}$ Data}

\subsection{The Investigation of the Gas Composition}

To obtain the correct $\mathrm{T}_{\mathrm{G}}$ in the ELCAD plasma, the first necessary condition is the accurate knowledge of gas composition of the ELCAD plasma. From the measurement of the minimum flow rate of the electrolyte cathode, which can still sustain the discharge for at least $10 \mathrm{~s}$, a cathode sputtering rate of $1,500 \mathrm{mg} / \mathrm{min}$ was obtained at a cathodic current density of $3.7 \mathrm{~A} / \mathrm{cm}^{2}$, a current of $80 \mathrm{~mA}$, and a $\mathrm{pH}=1.55$ (adjusted with $\mathrm{HCl}$ ). This means, that $5 \times 10^{22} \mathrm{H}_{2} \mathrm{O}$ molecules leave the electrolyte cathode each minute due to the cathode sputtering. After the ELCAD plasma is ignited in the atmospheric air, the plasma composition is changing very fast by the cathode sputtering.

This sputtering rate is higher by 3-4 orders of magnitude than those observed on metal cathodes. Since this high flux of the sputtered matter must leave the discharge plasma through its boundary surface, an overpressure builds up in the core of the plasma. Due to this overpressure, the solution cathode surface is depressed [29] and a pressure gradient appears between the plasma core and the outer, ambient air. Therefore, a significant gas flow from the plasma core to the ambient air occurs. In ELCAD, the $\mathrm{T}_{\mathrm{G}}$ values of $\sim 8,000-5,000 \mathrm{~K}$ were found from the ratio of the measured intensity of the $\mathrm{OH} 306.5 \mathrm{~nm}, 306.8 \mathrm{~nm}$ and $308.9 \mathrm{~nm}$ unresolved band heads [6], hence the thermal water splitting effect appears producing $\mathrm{H}$ and $\mathrm{OH}$ particles [30]. This multiplies further the rate of outward gas flow. Thus, the $\mathrm{OH}$ radicals produced in the plasma core leave the core of the cathode dark space and the negative glow with a velocity of 5-10 m/s. This totally obstructs the diffusion of any component of the ambient gas atmosphere into the ELCAD plasma [31]. Because of this extensive flushing process the ELCAD plasma operates in a self-generated saturated water vapor internal atmosphere. This is supported by the measured intensity distributions:

The intensity distribution of the $\mathrm{OH}-310 \mathrm{~nm}$ and the $\mathrm{N}_{2}-337 \mathrm{~nm}$ bands in the ELCAD measured by an ultraviolet sensitive CCD camera using the corresponding interference filters $\left(\lambda_{0}=310 \mathrm{~nm}\right.$, $\lambda_{0}=337 \mathrm{~nm}, \Delta \lambda=10 \mathrm{~nm}$ ). The Abel-inversion processing of these plasma pictures show that in the near cathode region, the plasma contains dominantly $\mathrm{OH}$ radicals, while $\mathrm{N}_{2}$ can be observed only in the outer sheath of the plasma (Figure 2 [31]).

The axial intensity distribution of $\mathrm{N}_{2}$ measured as a function of the distance from the anode showed only a peak in the close anode region, while it was very low at the other segment of the discharge. $\mathrm{N}_{2}$ 
can diffuse into the ELCAD plasma only at the near-anode region, since there the outflow of the plasma gases is practically negligible [6].

Figure 2. The radial distribution of the emitted intensity of $\mathrm{OH} 310 \mathrm{~nm}$ (squares) and the $\mathrm{N}_{2} 337 \mathrm{~nm}$ (circles) in the negative glow region of a typical ELCAD discharge ( $\mathrm{I}=67 \mathrm{~mA}$, tap water, $\mathrm{pH}=1.55)[31]$.

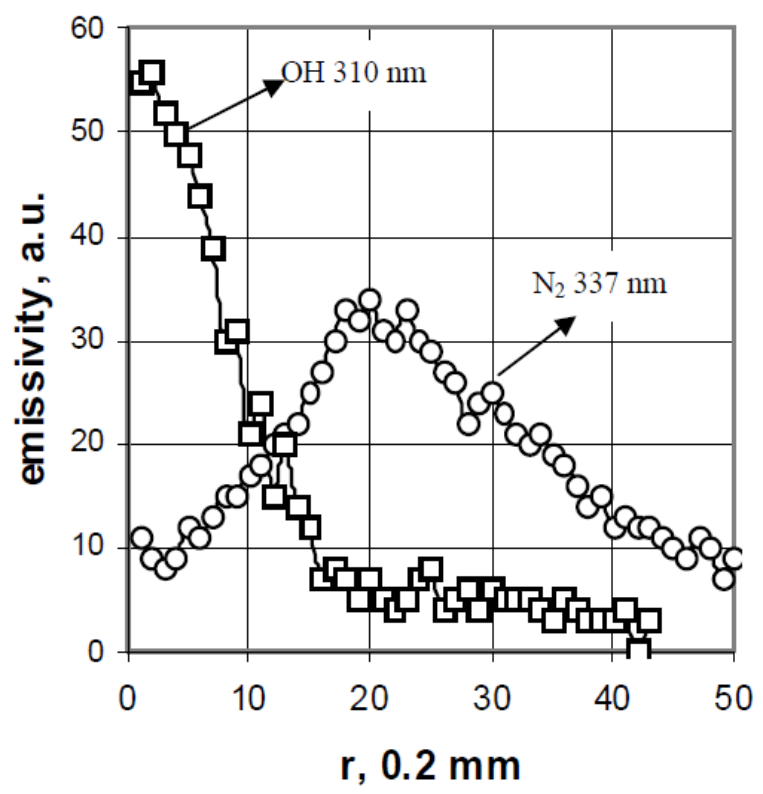

Since the ELCAD operates in a self-generated saturated water vapour with an atmospheric pressure, therefore the intensity of the $\mathrm{O}^{+}(441-445 \mathrm{~nm})$ lines, the $\mathrm{H}_{\beta}-486.1 \mathrm{~nm}$ line, the $\mathrm{OH}$ ultraviolet bands and the atomic lines of metals dissolved in the liquid electrolyte cathode were found to be independent from the applied outer gas atmosphere [4-6]. Considering these facts, the correct $\mathrm{T}_{\mathrm{G}}$ values in the ELCAD plasma can be determined only from the emitted intensity of the $\mathrm{OH}$ bands.

Furthermore, the $\mathrm{T}_{\text {rot }}$ rotational temperature of the ultraviolet $\mathrm{OH}\left(\mathrm{A}^{2} \sum, \mathrm{v}=0\right) \rightarrow \mathrm{OH}\left(\mathrm{X}^{2} \prod, \mathrm{v}=0\right)$ band was found to be close to the $T_{G}[32]$, and Izarra demonstrated that this $T_{\text {rot }}$ can be obtained from the measured intensity ratio of the $\mathrm{G}_{0}=306.5 \mathrm{~nm}$, the $\mathrm{G}_{1}=306.8 \mathrm{~nm}$ and the $\mathrm{G}_{\mathrm{ref}}=308.9 \mathrm{~nm}\left(\mathrm{G}_{0} / \mathrm{G}_{\text {ref }}\right.$; $\mathrm{G}_{1} / \mathrm{G}_{\mathrm{ref}}$ ) unresolved band heads [33]. He gave the $\mathrm{T}_{\text {rot }}$ values in $100 \mathrm{~K}$ steps as a function of the spectral resolution of the applied monochromator. The received $T_{\text {rot }}$ values were verified by an independent, interferometric measurement [34].

The result of other methods (the Boltzmann-plot, the simulation of emitted spectrum as a function of $\mathrm{T}_{\mathrm{G}}$ ), applied for determination of $\mathrm{T}_{\mathrm{G}}$ was not verified by an independent measurement [3,11-20]. Therefore, the Izarra method can be considered to be only a confirmed determination of the correct $\mathrm{T}_{\mathrm{G}}$ value in the ELCAD plasma.

\subsection{The $T_{e}$ Electron and the $T_{G}$ Gas Temperatures}

Since the ELCAD is an atmospheric glow discharge, thus $\mathrm{T}_{\mathrm{G}} \approx \mathrm{T}_{\mathrm{e}}$ can be expected [22-26]. This is valid only for the data in the first line of Table 1 . In this case, $T_{G}$ is determined from the emitted intensity of the $\mathrm{OH} 306-309 \mathrm{~nm}$ bands with using of Izarra method, while $\mathrm{T}_{\mathrm{e}}$ is obtained from the ratio of measured intensity of the $\mathrm{Cu}-\mathrm{I} 510.5 \mathrm{~nm}$ and $515.3 \mathrm{~nm}$ lines [4,6]. 
In all other cases, even if the $\mathrm{T}_{\mathrm{G}}$ determined from the emitted intensity of the $\mathrm{OH}$ bands, $\mathrm{T}_{\mathrm{e}}>>\mathrm{T}_{\mathrm{G}}$ was obtained. This was attributed to that the discharge plasma is not in the local thermodynamical equilibrium, but this explanation is a self-contradiction, since the Maxwell-Boltzmann distribution was applied for determination of $\mathrm{T}_{\text {rot }}$ by means of the Boltzmann-plot method and the simulation of the emitted spectrum of the $\mathrm{OH}$ bands.

The so called ionic temperature of $\mathrm{T}_{\text {ion }} \approx 4,623-5,038 \mathrm{~K}$ was determined from the Saha-Eggert equation with using the measured intensity of the Mg-I $285.2 \mathrm{~nm}$ and the Mg-II $279.5 \mathrm{~nm}$ lines [3,16]:

$$
n_{e} \cdot \frac{I_{k l}^{+} \cdot \lambda_{k l}^{+} \cdot A_{p q}}{I_{p q} \cdot \lambda_{p q} \cdot A_{k l}^{+}}=\left(\frac{2 g_{k}}{g_{p}}\right) \cdot\left(\frac{2 \pi \cdot m_{e} \cdot k \cdot T}{h^{2}}\right)^{3 / 2} \cdot \exp \left(\frac{-\left(E_{i}+E_{k}-E_{p}\right)}{k \cdot T}\right)
$$

where $I_{k l}^{+}, \lambda^{+}{ }_{k l}, A^{+}{ }_{k l}$ and $E_{k}$ are the measured intensity, the wavelength, the transition probability and the upper level energy of the Mg-II $279.5 \mathrm{~nm}$ transition. $I_{p q}, \lambda_{p q}, A_{p q}$ and $E_{p}$ are the same physical quantities corresponding to the Mg-I $285.2 \mathrm{~nm}$ transition. In this way, in the negative glow $\mathrm{T}_{\text {ion }}=(5,038 \pm 60) \mathrm{K}$, and in the positive column $\mathrm{T}_{\text {ion }}=(4,623 \pm 34) \mathrm{K}$ values were obtained $[3,16]$.

Equation (1/a) can be obtained from the Saha-Equation [27,28]

$$
\frac{n_{e} \cdot n_{i}}{n_{n}}=G \cdot\left(\frac{2 \pi \cdot m_{e} \cdot k \cdot T_{G}}{h^{2}}\right)^{3 / 2} \cdot \exp \left(\frac{-e \cdot U_{i}}{k \cdot T_{G}}\right)
$$

if the density of the neutral $\left(n_{n}\right)$ and the ionic $\left(n_{i}\right)$ particles is described by the Boltzmann distribution:

$$
n_{n}=n_{n 0} \cdot \exp \left(-\frac{E_{p}}{k T_{e}}\right), n_{i}=n_{i 0} \cdot \exp \left(-\frac{E_{k}}{k T_{e}}\right)
$$

the emitted intensities are:

$$
I_{p q}=n_{n} A_{p q} h c / \lambda_{p q}, I_{k l}^{+}=n_{i} A_{k l}^{+} h c / \lambda_{k l}^{+}
$$

and:

$$
T_{G}=T_{e}
$$

The conditions of Equations (2) and (4) can be applied for the ELCAD, since the excitations are mostly the electron impacts in it and it is an atmospheric glow discharge. Because of Equation (4), the received $\mathrm{T}_{\text {ion }} \approx 4,623-5,038 \mathrm{~K}$ is not the so called ionic, but this is really the common temperature of $\mathrm{T}_{\mathrm{G}}=\mathrm{T}_{\mathrm{e}}$. Therefore, the $\mathrm{T}_{\text {rot }} \approx 3,200-3,600 \mathrm{~K}$ gas temperature determined from the emitted intensity of the $\mathrm{OH} 306 \mathrm{~nm}$ band is inaccurate.

\section{3. $T_{G}$ and $n_{e}$ Values and the Engel-Brown Approximation}

The Saha-equation concerns the highly ionized plasmas with high charge densities [27,28]. But the glow discharges are weakly ionized plasmas, hence their charge densities are very low. Since the ELCAD is also a glow discharge, hence, instead of Saha-equation, the Engel-Brown approximation given for glow discharges $[8,10]$ is used for checking the published $\mathrm{T}_{\mathrm{G}}$ and $n_{e}$ values:

$$
\frac{n_{e}}{n_{n}} \sim \exp \left(\frac{-e U_{i}}{2 \cdot k \cdot T_{G}}\right)
$$


where $n_{e}$ and $n_{n}$ are the electron and neutral particle densities, $e$ is the elementary charge, $k$ is the Boltzmann constant and $U_{i}$ is the ionization potential of the gas.

The dependence of $n_{n}$ neutral gas particle density on the gas pressure and the gas temperature is [9]:

$$
n_{n}\left[\mathrm{~cm}^{-3}\right]=\frac{3.3 \cdot 10^{16} \cdot p[\text { torr }] \cdot 298[\mathrm{~K}]}{T_{G}[K]}
$$

Combining the Equations (5) and (6) and taking into account that the ELCAD operates in a saturated atmospheric pressure water vapour, thus $p=760$ torr and $e U_{i}=2 \times 10^{-18} \mathrm{~J}$, we have:

$$
n_{e}\left[\mathrm{~cm}^{-3}\right] \sim \frac{7.35 \cdot 10^{21}}{T_{G}} \cdot \exp \left(\frac{-2 \cdot 10^{-18}}{2.76 \cdot 10^{-23} \cdot T_{G}}\right)
$$

The published $\mathrm{T}_{\mathrm{G}}$ and $n_{e}$ values are compared with the results obtained from Equation (7). The $n_{e} \approx 2.1 \times 10^{13} \mathrm{~cm}^{-3}$ value was estimated [4,21] at the end of the cathode dark space, where $n_{e} \approx n^{+}$(= positive ion density) [8-10]. To obtain the $\mathrm{n}_{\mathrm{e}}$ value in the negative glow, this latter result needs a refinement due to the general charge density distributions.

For this saturated, atmospheric water vapour plasma, reliable simulated charge density distributions confirmed by experiments cannot be found in the literature. Therefore, the $n_{e}$ value in the negative glow can be estimated only on the base of two different general charge density distributions for glow discharges:

(a) The von Engel distribution indicates that $n_{e}$ in the negative glow is higher by a factor of $\sim 1.5$ than that at the end of cathode dark space [10]. Thus:

$$
n_{e} \approx 3 \times 10^{13} \mathrm{~cm}^{-3}
$$

(b) The Raizer distribution shows that $\mathrm{n}_{\mathrm{e}}$ in the negative glow is lower by a factor of $\sim 0.5$ compared with that at the end of cathode dark space [9], hence:

$$
n_{e} \approx 1 \times 10^{13} \mathrm{~cm}^{-3}
$$

In an ELCAD-type discharge, the radial distribution of the $n_{e}$ electron density was determined from the measured Stark-broadening of the $\mathrm{H}_{\beta}-486.1 \mathrm{~nm}$ line. In the negative glow:

$$
n_{e}=(8.5 \pm 1.9) \times 10^{14} \mathrm{~cm}^{-3}
$$

and in the positive column:

$$
n_{e}=(2.5 \pm 0.5) \times 10^{14} \mathrm{~cm}^{-3}
$$

was obtained [16], but in contrast with the $n_{e}(r)$ distribution for the positive column, the $n_{e}$ distribution for the negative glow $(0.2 \mathrm{~mm}$ above the cathode!) exhibits an unbelievably constant and noiseless value in this publication. Such an extraordinary statistical parameter immediately generates the assumption of an instrumental error source instead of true measurement data. Perhaps the plasma position was inadequate and the naturally noisy negative glow was out of the observation line, and most probably the mirrored anode glow was observed in fact. Hence, the $\mathrm{n}_{\mathrm{e}}$ value for the negative glow given by Equation (9) is erroneous.

Applying Equation (7), the evaluation of the published $\mathrm{T}_{\mathrm{G}}$ and $n_{e}$ values presented in Table 1 can be summarized by a combined plot shown by Figure 3. 
Figure 3. Published $n_{e}$ and $T_{G}$ data pairs for ELCAD and its homolog discharge plasmas. Solid curve represents the equilibrium parameters calculated for $\mathrm{H}_{2} \mathrm{O}$ vapor by the von Engel-S.C.Brown approximation (7). [6,21/a] and [6,21/b] points are due to the data of Equations (8/a) and (8/b).

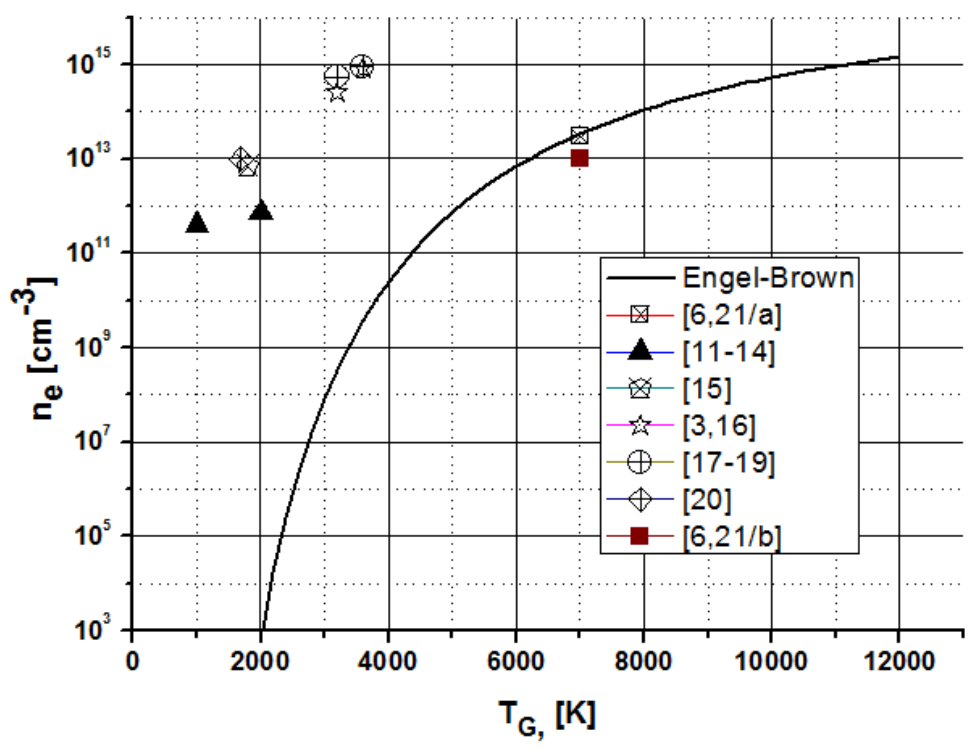

Figure 3 shows that the use of the $\mathrm{N}_{2}$ emission for investigation of the plasma core is misleading due to the fact that the plasma core in the negative glow does not contain components of the ambient atmosphere.

Except the $\mathrm{T}_{\mathrm{G}} \approx 7,000 \mathrm{~K}$ and $n_{e} \approx(1-3) \times 10^{13} \mathrm{~cm}^{-3}$ values [6,21], the published $\mathrm{n}_{\mathrm{e}}$ electron density and the $\mathrm{T}_{\mathrm{G}}$ gas temperature data pairs are very far from the von Engel equilibrium curve (solid line) calculated for $\mathrm{H}_{2} \mathrm{O}$ vapor. In accordance with the usual, classical readings, the error of temperatures presented on Figure 3, is about $\sim 2,500-9,000 \mathrm{~K}$. On the other hand, the published electron density values are higher with about two orders of magnitude compared with the expected one.

\section{Conclusions}

The evaluation of the published data performed by means of Equation (3) shows that in most of the cases, the obtained $T_{\text {rot }}$ rotational temperature and $n_{e}$ electron density values are not consistent with each other. Generally, the obtained $\mathrm{T}_{\text {rot }}$ values are much lower, while the determined $n_{e}$ values are very much higher compared with those can be received from Equation (7). The main reasons of this are the following:

(1) It is not yet widely understood that ELCAD plasmas operate in saturated $\mathrm{H}_{2} \mathrm{O}$ vapor due to the very intense sputtering of the aqueous cathode. Hence, the gas temperature determination based on the emitted spectrum of $\mathrm{N}_{2}$ molecule being only in the outer sheath cannot give the correct, real gas temperature data of the plasma.

(2) For determination of $\mathrm{T}_{\mathrm{G}}\left(\approx \mathrm{T}_{\text {rot }}\right)$ in the ELCAD technique, the method of de Izarra giving $\mathrm{T}_{\text {rot }}$ from the ratio of the measured unresolved ultraviolet band heads of $\mathrm{OH}$ proved to be the only reliable method. These $\mathrm{T}_{\text {rot }}$ values were verified by an independent, interferometric measurement $[33,34]$. 
(3) A serious conceptual confusion can be found in the interpretation of the temperature results. The $T_{e} \gg T_{\text {rot }}$ values obtained from the emitted spectrum simulation and the Boltzmann plot method were attributed to the fact that the investigated ELCAD plasma is not in a local thermodynamic equilibrium. But this is a self-contradiction, since the Maxwell-Boltzmann distribution was applied for determination of the temperatures. These could be avoided if $\mathrm{T}_{\mathrm{G}}=\mathrm{T}_{\mathrm{e}}$ are used for the mutual validation of the received temperature data. A thorough evaluation of the experiments and the simulations calculations could help to find the possible error sources causing these incorrect temperature values.

(4) The experimental determinations of the $n_{e}$ electron density refer to that the limit of the applied experimental methods were not presented, since often they were not taken into account. In certain cases, the theoretical determination of $n_{e}$ is too complicated and confusing, moreover it neglects the basic properties of the ELCAD plasma.

(5) Some investigations of this "exotic" plasma seem to be loaded with serious experimental errors:

- ambiguous plasma conditions (e.g., distilled water cathode without recording of the steeply changing $\mathrm{pH}$ and conductivity values of the cathode solution during the plasma operation)

- plasma probing with low spatial resolution technique (e.g., the received values cannot be linked to the relevant parts of this plasma of small physical dimensions, $\mathrm{V} \sim 10 \mathrm{~mm}^{3}$ )

- considering the small physical dimensions of the plasma, a misaligned optical system can easily produce meaningless results.

Generally in the reviewed publications the prime rule of the experimental research is frequently missing: the experiment must be as precise as the theoretical base of the evaluation, in other words the quality of the measured data determines the reliability of the evaluation results. Without a strictly designed experimental setup using adequate techniques fitting to the characteristics of the specimen to be investigated, only conclusions of low validity can be derived, even with applying the most sophisticated theoretical treatments.

\section{Acknowledgement}

This work was supported by the Hungarian Scientific Research Foundation (OTKA) under the project number of K 68390.

\section{References}

1. Cserfalvi, T.; Mezei, P.; Apai, P. Emission studies on a glow discharge in atmospheric pressure air using water as a cathode. J. Phys. D Appl. Phys. 1993, 26, 2184-2188.

2. Cserfalvi, T.; Mezei, P. Subnanogram sensitive multimetal detector with atmospheric electrolyte cathode glow discharge. J. Anal. At. Spectrom. 2003, 18, 596-602.

3. Webb, M.R.; Andrade, F.J.; Gamez, G.; McCrindle, R.; Hieftje, G.M. Spectroscopic and electrical studies of a solution-cathode glow discharge. J. Anal. At. Spectrom. 2005, 20, 1218-1225.

4. Mezei, P.; Cserfalvi, T. Electrolyte cathode atmospheric glow discharges for direct solution analysis. Appl. Spectrosc. Rev. 2007, 42, 573-604. 
5. Mezei, P.; Cserfalvi, T.; Jánossy, M. Pressure dependenc of the atmospheric electrolyte cathode glow discharge spectrum. J. Anal. At. Spectrom. 1997, 12, 1203-1208.

6. Mezei, P.; Cserfalvi, T.; Csillag, L. The spatial distribution of the temperatures and the emitted spectrum in the electrolyte cathode atmospheric glow discharge. J. Phys. D Appl. Phys. 2005, 38, 2804-2811.

7. Massey, H.S.W.; Burhop, E.H.S.; Gilbody, H.B. Recombination. In Electronic and Ionic Impact Phenomena; Massey, H.S.W., Gilbody, H.B., Eds.; Clarendon: Oxford, UK, 1974.

8. Brown, S.C. Introduction to Electrical Discharges in Gases; John Wiley: New York, USA, 1966.

9. Raiser, Y.P. Gas Discharge Physics; Springer: Berlin, Germany, 1991.

10. Von Engel, A.; Ionized Gases; Clarendon: Oxford, UK, 1965.

11. Afanasev, V.P.; André, P.; Barinov, Y.A.; Faure, G.; Kaplan, V.B.; Lefort, A.; Shkolnik, S.M. Theoretical and experimental investigation of a discharge with liquid nonmetallic electrodes in air at atmospheric pressure. In Proceedings Contributed Papers of XXIII International Conference on Phenomena in Ionized Gases, Toulouse, France, 17-22 July 1997; Volume III, p. 104.

12. Faure, G.; Shkolnik, S.M. Determination of rotational and vibrational temperatures in a discharge with non-metallic electrodes in air at atmospheric pressure. J. Phys. D Appl. Phys. 1998, 31, 1212-1218.

13. André, P.; Barinov, Y.A.; Faure, G.; Kaplan, V.; Lefort, A.; Shkolnik, S.M.; Vacher, D. Experimental study of discharge with liquid non-metallic (tap-water) electrodes in air at atmospheric pressure. J. Phys. D Appl. Phys. 2001, 34, 3456-3465.

14. André, P.; Aubreton, J.; Barinov, Y.A.; Elchinger, M.F.; Fauchais, P.; Faure, G.; Kaplan, V.; Lefort, A.; Rat, V.; Shkolnik, S.M. Theoretical study of column of discharge with liquid non-metallic (tap-water) electrodes in air at atmospheric pressure. J. Phys. D Appl. Phys. 2002, $35,1846-1854$.

15. XinPei, L.; Leipold, F.; Laroussi, M. Optical and electrical diagnostics of a non-equilibrium air plasma. J. Phys. D Appl. Phys. 2003, 36, 2662-2666.

16. Webb, M.R.; Chan, G.C.-Y.; Andrade, F.J.; Gomez, G.; Hieftje, G.M. Spectroscopical characterization of ion and electron populations in solution-cathode glow discharge. J. Anal. At. Spectrom. 2006, 21, 525-530.

17. Bruggeman, P.; Liu, J.; Degroote, J.; Kong, M.G.; Vierendeels, J.; Leys, Ch. Dc excited glow discharges in atmospheric pressure air inpin-to-water electrode systems. J. Phys. D Appl. Phys. 2008, doi: 10.1088/0022-3727/41/21/215201.

18. Bruggeman, P.; Leys, C. Non-thermal plasmas in and in contact with liquids. J. Phys. D Appl. Phys. 2009, doi: 10.1088/0022-3727/41/5/053001.

19. Bruggeman, P.; Ribezl, E.; Maslani, A.; Degroote, J.; Malesevic, A.; Rego, R.; Vierendeels, J.; Leys, C. Characteristics of atmospheric pressure air discharges with liquid cathode and a metal anode. Plasma Source Sci. Technol. 2008, doi: 10.1088/0963-0252/17/2/025012.

20. Titov, V.A.; Rybkin, V.V.; Smirnov, S.A.; Kulentsan, A.L.; Choi, H.S. Experimental and theoretical studies on the characteristics of atmospheric pressure glow discharge with liquid cathode. Plasma Chem. Plasma Process. 2006, 26, 543-555.

21. Mezei, P.; Cserfalvi, T. Charge densities in the electrolyte cathode atmospheric glow discharges (ELCAD). Eur. Phys. J. Appl. Phys. 2007, 40, 89-94. 
22. Houben, J.M.; Zaat, J.H. Analysis of a Plasma Torch. Available online: http://alexandria.tue.nl/ repository/freearticles/604508.pdf (accessed on 24 April 2012).

23. Meichsner, J. Introduction to Plasma Physics, Lecture on European Summer School Plasma Physics in Science and Technology. Available online: http://ppst-physik.uni-greifswald.de/ Meichsner-PPST-2009-Prague.pdf (accessed on 24 April 2012).

24. Massey, T.J. Constricted discharges in rare gases II. Analysis of the macroscopic properties of the discharges. J. Appl. Phys. 1965, 36, 373-380.

25. Elenbaas, W. Ligth Sources; Crane Russak: New York, NY, USA, 1972.

26. Penning, F.M. Electrical Discharges in Gases; Cleaver-Hume Press: London, UK, 1957.

27. Simonyi, K. Physikalische Elektronik; Akadémiai Kiadó: Budapest, Hungary, 1972.

28. Chen, F.F. Introduction to Plasma Physics and Controlled Fusion; Plenum Press: New York, NY, USA, 2008; Volume 1.

29. Mezei, P.; Cserfalvi, T.; The investigation of an abnormal electrolyte cathode atmospheric glow discharge (ELCAD). J. Phys. D Appl. Phys. 2006, 39, 1-6.

30. Boudesocque, N.; Vandensteendam, C.; Lafon, C.; Girold, C. Hydrogen production by thermal water splitting using a thermal plasma. In Proceedings of 16th World Hydrogen Energy Conference (WHEC 16), Lyon, France, 13-16 June 2006

31. Cserfalvi, T.; Mezei, P. The radial emissivity distribution of $\mathrm{N}_{2}-337 \mathrm{~nm}$ and $\mathrm{OH}-306 \mathrm{~nm}$ bands in the electrolyte cathode atmospheric glow discharge (ELCAD). Posters of the Colloqium Spectroscopicum Internationale XXXVI, Budapest, Hungary, 30 August-3 September 2009; Poster PW-85; CSI XXXVI compact disc, ISBN: 978-963-9319-97-4.

32. Pellerin, S.; Cormier, J.M.; Richard, F.; Musiol, K.; Chapelle, J. A spectroscopic diagnostic method using UV OH band spectrum. J. Phys. D Appl. Phys. 1996, 29, 726-739.

33. De Izarra, C. UV OH spectrum used as molecular pyrometer. J. Phys. D Appl. Phys. 2000, 33, 1697-1704.

34. Rabat, H.; de Izarra, C. Check of $\mathrm{OH}$ rotational temperature using an interferometric method. J. Phys. D Appl. Phys. 2004, 37, 2371-2375.

(C) 2012 by the authors; licensee MDPI, Basel, Switzerland. This article is an open access article distributed under the terms and conditions of the Creative Commons Attribution license (http://creativecommons.org/licenses/by/3.0/). 